\title{
An Experimental Study on the Microstructures of Cemented Paste Backfill during Its Developing Process
}

\author{
Bo Zhang $\mathbb{D}^{1},{ }^{1}$ Jie Xin, ${ }^{1}$ Lang Liu $\left(\mathbb{D},{ }^{1,2}\right.$ Lijie Guo $\left(\mathbb{D},{ }^{3}\right.$ and Ki-Il Song $\mathbb{D}^{4}$ \\ ${ }^{1}$ Energy School, Xi'an University of Science and Technology, Xi'an 710054, China \\ ${ }^{2}$ Key Laboratory of Western Mines and Hazard Prevention, Ministry of Education of China, Xi'an 710054, China \\ ${ }^{3}$ Beijing General Research Institute of Mining \& Metallurgy, Beijing 100160, China \\ ${ }^{4}$ Department of Civil Engineering, Inha University, Incheon 402-751, Republic of Korea \\ Correspondence should be addressed to Lang Liu; liulang@xust.edu.cn
}

Received 18 April 2018; Accepted 2 July 2018; Published 8 October 2018

Academic Editor: Flora Faleschini

Copyright (c) 2018 Bo Zhang et al. This is an open access article distributed under the Creative Commons Attribution License, which permits unrestricted use, distribution, and reproduction in any medium, provided the original work is properly cited.

\begin{abstract}
The aim of this study was to examine the microstructure of cemented paste backfill (CPB) during its development and relate the characteristics of the microstructure to the physical and mechanical properties of CPB. The geometry and morphology of the microstructures of CPB were observed by the scanning electron microscopy (SEM). The characteristics including pore size, pore shape, and orientation of the microstructures of CPB at different curing times were analyzed based on the SEM images. The porosity, fractal dimension, and probability entropy were characterized using the Particles and Pore Recognition and Analysis System (PPRAS). It was found that the pore size, pore shape, and orientation of the microstructure of CPB significantly change as the curing time increases, resulting in the increase of UCS. Meanwhile, the arrangement of the pores affects the mechanical properties of $\mathrm{CPB}$. At the early age of CPB development, the probability entropy is above 0.96 , indicating a chaotic pore distribution and no obvious orientation. At the late age of CPB development, the probability entropy becomes smaller and the order and orientation of the pore distribution are enhanced, leading to an increase in USC. The UCS of CPB is also greatly affected by the characteristics of the pore morphology. During the development of CPB, the pore shape becomes smoother. The UCS of CPB approximately linearly improves with an increase in the average roundness of pores.
\end{abstract}

\section{Introduction}

The backfill mining method has gained more and more focuses in the recent years due to its good economic and social benefits and industrial rewards. As the environment protection has become more important, the mine sites which were exploited using the open stope mining method and caving mining method have been switched to be mined by the backfill mining method as well [1-3]. The backfill mining method also has shown its importance on deep mining, controlling the ground pressure and surface subsidence and protecting the ecological environment [4-6].

In recent years, many studies have been carried out to study the macroscopical characteristics, microstructure, or the mechanical characteristics of CPB. Keshimal studied the relationship between the desliming copper-lead tailings and the strength of backfill paste [7]. It was found that the particle size distribution of the tailing solids had significant effect on the strength of the backfill paste. Fall et al. studied the effect of curing temperature on the mechanical properties of tailings backfill [8]. Deng et al. studied the cement type and proportion, the aggregate ingredients and distribution, the water quality and proportion, additives, stirring time, curing time, and curing temperature on $\mathrm{CPB}$ with fine aggregates systematically [9]. Hydration products of magnesium phosphate cement specimens at different hydration temperatures were analyzed using XRD and SEM, which showed that $\mathrm{NH}_{4} \mathrm{MgPO}_{4} \cdot 6 \mathrm{H}_{2} \mathrm{O}$ was the main hydration product, and the temperature below $70^{\circ} \mathrm{C}$ benefited the strength growth of CPB [10]. SEM was also used to 
determine the proportion of anhydrous cement, which indicated that the rate of hydration increased significantly with the $10 \mathrm{wt} . \%$ and $25 \mathrm{wt} . \%$ of anhydrous cement [11]. Deng et al. found that the main parameter that affected the mechanical properties of the backfill was the particle size distribution of the tailings [12]. Zhou et al. studied the microstructure of Guangzhou soft soil during the consolidation process using the Environmental Scanning Electron Microscopy (ESEM) and found that the increase of consolidation pressure resulted in the scale increase of structural units of the soil and the orientation, and the decrease of the soil porosity and the fractal dimension [13]. Cao et al. studied the microstructure of soft soil under different cyclic stress ratios and vibration frequencies using scanning electron microscopy (SEM) and Particle and Pore Recognition and Analysis System (PPRAS). The effects of cyclic stress ratios and frequencies on the microstructure of soft clay under wave loading were revealed according to the variation of microstructural parameters before and after the cyclic loading, and the microscopic mechanism of wave loading was also disclosed [14]. Zhou et al. studied the compression tests for structured clay in Hangzhou to investigate the compression and its mechanism of microstructure changes during the consolidation process. It was found that the pore characteristics of the soft clay, including scale, distribution, arrangement, and pattern all significantly changed as the consolidation pressure increased [15]. Xu et al. tested the microstructure evolution and long-term strength model of $\mathrm{CPB}$ under different ratios of cement to sand, slurry mass concentrations, and aging times. They also studied the effects of types and forms of hydration reaction production within backfill on the strength model. It was found that the types and speciation of hydration products varied as the curing time changed [16].

The studies above mainly analyzed the mechanical properties of CPB in a macroscopic scale. Only mechanical properties and microstructures of soft clays were analyzed in the microscopic scale. In the study of CPB, rarely studies have correlated the microstructural parameters with mechanical responses. In order to increase the quality of $\mathrm{CPB}$, further studies are necessary to evaluate the relationship between the microstructure and the engineering properties. It has been shown that the microstructural parameters, including particle shape, size distribution, arrangement and connecting style, microparticle scale, paste type, pore size, and porosity, are responsible for the mechanical properties of the paste backfill. The variety and randomicity of the microstructure of $\mathrm{CPB}$ resulted in the variety and randomicity of the macrostructure of the backfill. Therefore, the study of microstructure of $\mathrm{CPB}$ will be helpful in understanding the $\mathrm{CPB}$ engineering properties.

In this study, the SEM was used to obtain the images of microstructure to study the scale, shape, orientation, and the developing process of $\mathrm{CPB}$, and the images were processed using PPRAS to obtain the microstructural parameters of $\mathrm{CPB}$. The changing rules of the porosity, fractal dimension, and probability entropy with UCS were investigated, which can be used as guidelines for practical backfill applications of $\mathrm{CPB}$.

\section{Materials and Methods}

\subsection{Materials Used}

2.1.1. Tailings. The tailings utilized in this study are from a pyrite mineral process plant, located at Anhui Province of China. According to the Specification of Soil Test, that is, SL 237-1999, SL 237-005-1999, and SL 237-004-1999 [17], the specific gravity, bulk density, and porosity of tailings were measured and are listed in Table 1 . The particle size distribution (PSD) of tailings is presented in Figure 1, which shows that $d_{10}, d_{50}, d_{60}$, and $d_{90}$ are $4.96 \mu \mathrm{m}, 23.84 \mu \mathrm{m}$, $32.00 \mu \mathrm{m}$, and $71.30 \mu \mathrm{m}$, respectively, and the nonuniformity coefficient of the tailing particles is 6.45 . Hence, it could be classified as a gap gradation type, indicating that the tailings used relatively lack of large particles. Furthermore, the main chemical compositions of tailings were tested in Beijing General Research Institute of Mining \& Metallurgy (BGRIMM), and the details are listed in Table 2, indicating that the high content of sulphide has some damaging effect on the quality (e.g., strength deterioration) of cement-based backfill materials [18].

2.1.2. Water and Binders. The water used in this study is common tap water. Portland cement (P.O. 32.5) is selected as the binder for $\mathrm{CPB}$, and the main physical properties and chemical compositions are shown in Tables 3 and 4, respectively.

\subsection{Methods}

2.2.1. CPB Specimen Preparation. CPB was characterized as a mixture of tailings, binder (P.O. 32.5 Portland cement), and water, at $70.15 \mathrm{wt} . \%, 5.85 \mathrm{wt} . \%$, and $24 \mathrm{wt} . \%$, respectively, which was mixed and homogenized in a double spiral mixer. The prepared CPB slurry with different mix ratios was poured into the curing moulds, that is, $10 \mathrm{~cm}$ in diameter and $20 \mathrm{~cm}$ height cylindrical containers, and labeled. After 24 hours, the specimens were demoulded and put into the curing box under a given curing environment (temperature $20 \pm 1^{\circ} \mathrm{C}$ and humidity $95 \% \pm 1 \%$ ). Then, the SEM and USC were conducted for the specimens at different curing times of $3 \mathrm{~d}, 7 \mathrm{~d}, 14 \mathrm{~d}, 28 \mathrm{~d}, 56 \mathrm{~d}$, and $90 \mathrm{~d}$.

2.2.2. Scanning Electron Microscopy. In order to obtain the real microstructure of $\mathrm{CPB}$, the $\mathrm{CPB}$ before and after development was pushed out gently from the ring knife using the permeable stone. A raw specimen was obtained by cutting the middle part of $\mathrm{CPB}$ using a Vaseline-coated wire saw, and then a double-sided blade was used to cut the specimen around the side with a width of around $1.5 \mathrm{~mm}$ to get a specimen with a natural and flat surface. Following this, the specimen was further cut into a cylinder with $5 \mathrm{~mm}$ diameter and $5 \mathrm{~mm}$ height for easy observation using SEM [15]. The surface of the CPB specimen was kept smooth and neat, and the particles on the surface was blown off using aurilave before subjecting to SEM scan. The SEM images of 
TABLE 1: Basic physical properties of tailings used in this study.

\begin{tabular}{lcccc}
\hline Item & Specific gravity $\left(\mathrm{t} / \mathrm{m}^{3}\right)$ & Volume weight $\left(\mathrm{t} / \mathrm{m}^{3}\right)$ & Bulk density $\left(\mathrm{t} / \mathrm{m}^{3}\right)$ & Porosity $(\%)$ \\
\hline Tailings & 2.852 & 1.387 & 0.487 & 51.370 \\
\hline
\end{tabular}

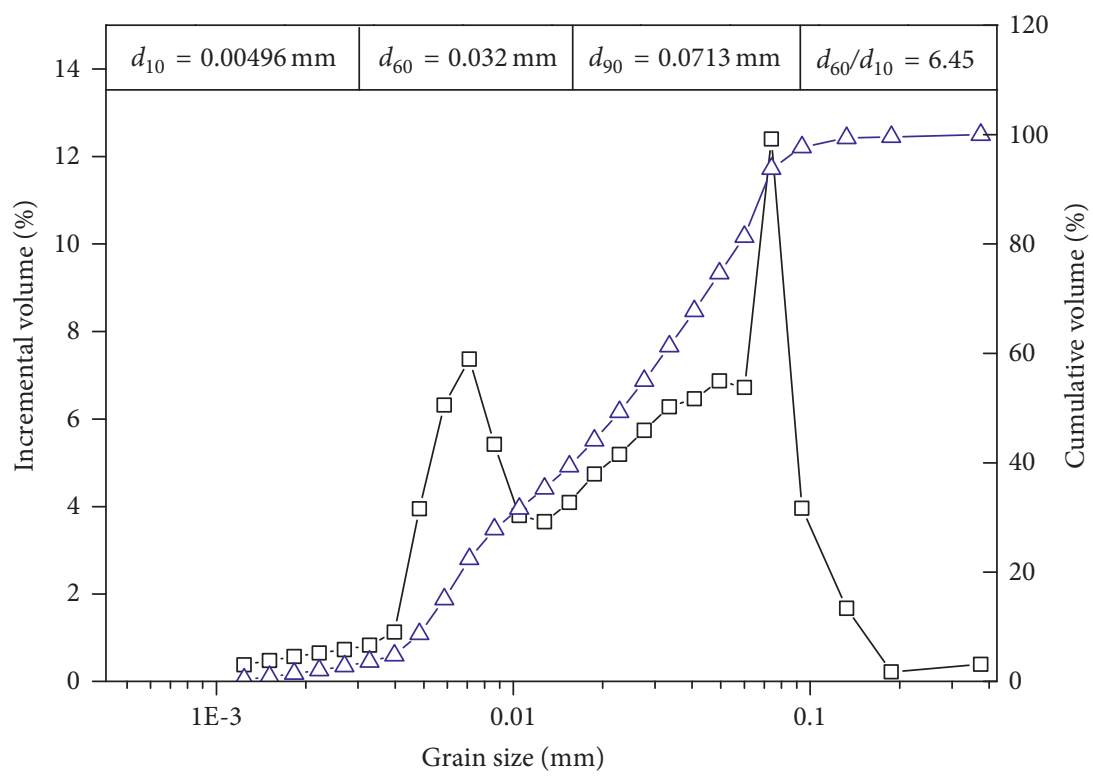

$-\triangle$ - Cumulative volume

- - - Incremental volume

FIgURE 1: The particle size distribution of tailings.

TABle 2: Chemical composition of tailings used (units: wt.\%).

\begin{tabular}{lccccccc}
\hline Item & $\mathrm{TFe}$ & $\mathrm{SiO}_{2}$ & $\mathrm{Al}_{2} \mathrm{O}_{3}$ & $\mathrm{CaO}$ & $\mathrm{MgO}$ & $\mathrm{Cu}$ & $\mathrm{S}$ \\
\hline Tailings & 18.57 & 40.02 & 4.17 & 24.07 & 6.10 & 0.11 & 5.68 \\
\hline
\end{tabular}

Table 3: Main physical properties of P.O. 32.5 Portland cement.

\begin{tabular}{lcc}
\hline Items & Value & Reference \\
\hline Fineness $(<0.045 \mathrm{~mm})(\%)$ & 11.00 & $\leq 30$ \\
Initial setting time $(\mathrm{min})$ & 162.00 & $\geq 45$ \\
Final setting time $(\mathrm{min})$ & 203.00 & $\leq 390$ \\
28-day flexural strength $(\mathrm{MPa})$ & 6.60 & 6.5 \\
28-day uniaxial compressive strength $(\mathrm{MPa})$ & 31.50 & 32.5 \\
\hline
\end{tabular}

Note: reference of P.O. 32.5 Portland cement is from China's cement strength classification.

the prepared CPB at different curing times, that is, $3 \mathrm{~d}, 7 \mathrm{~d}$, 14 d, 28 d, 56 d, and 90 d, are shown in Figure 2.

2.2.3. Quantitative Analysis System. The SEM images were quantitatively analyzed using the Particles and Pore Recognition and Analysis System (PPRAS) developed by Liu et al. [19]. The procedure is described as follows: using image processing technology, the original SEM pictures can be processed into binary pictures and vector pictures. For example, Figure 3 shows the binary image of CPB. The black and white areas represent particles and pores, respectively. But there are many dots in the white areas. The corresponding vector processing results are shown in Figure 4.
The black areas represent particles and other color areas are pores. It is found that small dots are removed. Then, the statistical quantitative parameters, including average pore area, pore ratio, pore volume, porosity, porosity fractal dimension, probability entropy, average shape factor, and the fractal dimension, can be obtained.

2.2.4. UCS Test. The UCS test is a widely accepted and easy method to evaluate the quality of CPB [20]. In this study, the $\mathrm{CPB}$ specimens with different curing times, that is, $3 \mathrm{~d}, 7 \mathrm{~d}$, $14 \mathrm{~d}, 28 \mathrm{~d}, 56 \mathrm{~d}$ and $90 \mathrm{~d}$, were prepared, and the height and diameter of each specimen were measured before the UCS test. Then, the UCS tests were carried out on CPB specimens using MTS-C43.504 with a normal capacity of $20 \mathrm{kN}$ and the displacement rate of $1 \mathrm{~mm}$ per min, and the operating instructions were previously described in [21].

\section{Results and Discussion}

\subsection{Characteristics of Pore Size and Pore Size Distribution}

3.1.1. Characteristics of Pore Size. The porosity is defined as the proportion between pore area and particle area. Although it was a two-dimensional parameter, it could still indirectly reflect the change of porosity in three-dimensional space [15]. Figure 5(a) shows the variation of UCS with the change of porosity. It shows that the UCS increases significantly as the porosity decreases at the early age of CPB 
Table 4: Main chemical compositions of P.O. 32.5 Portland cement.

\begin{tabular}{lcccccccc}
\hline Compositions & $\mathrm{CaO}$ & $\mathrm{SiO}_{2}$ & $\mathrm{Al}_{2} \mathrm{O}_{3}$ & $\mathrm{Fe}_{2} \mathrm{O}_{3}$ & $\mathrm{MgO}$ & $\mathrm{SO}_{2}$ & $\mathrm{Na}_{2} \mathrm{O}$ & $\mathrm{Other}$ \\
\hline Percentage & 63.66 & 21.26 & 4.50 & 2.80 & 1.66 & 2.58 & 0.18 & 2.66 \\
\hline
\end{tabular}

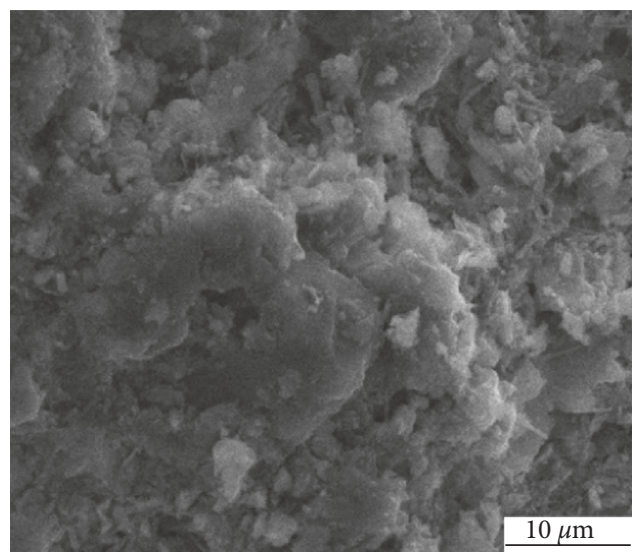

(a)

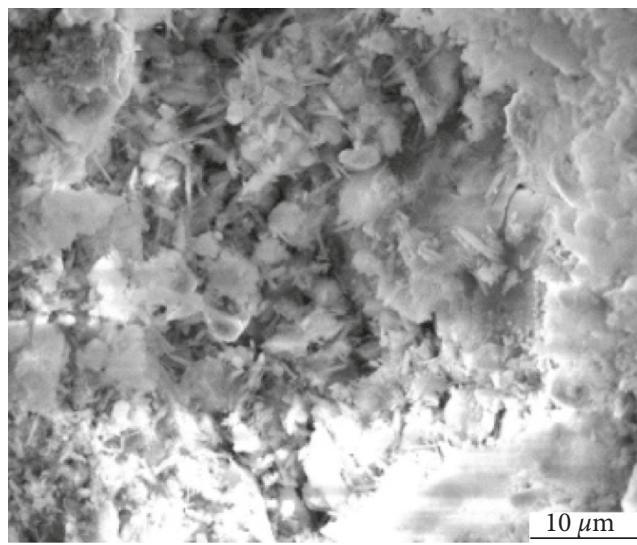

(c)

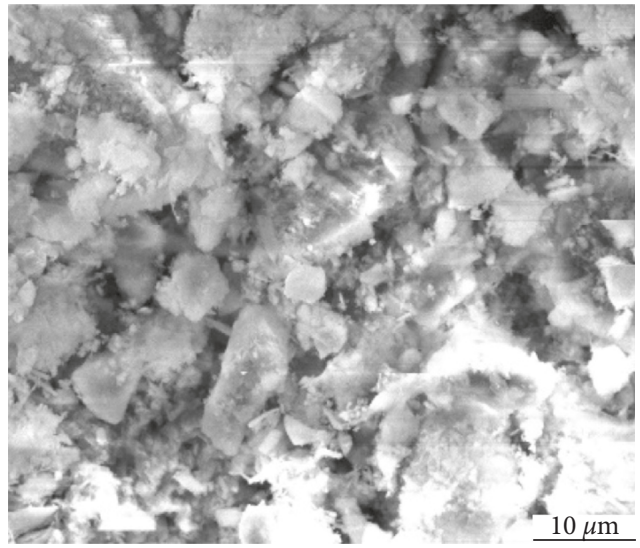

(e)

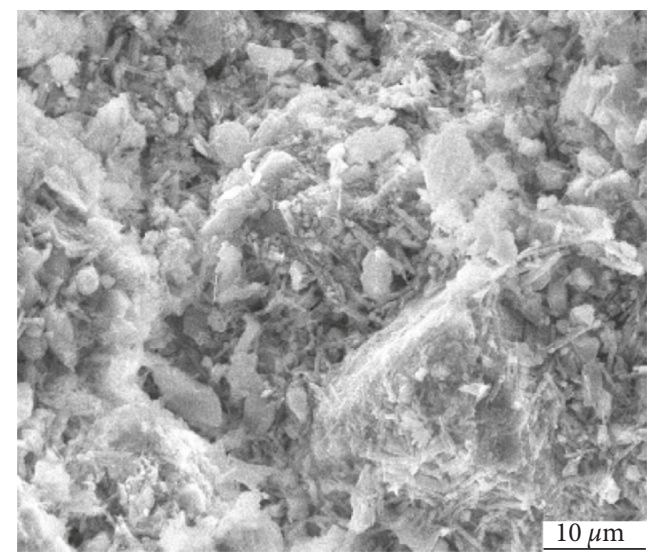

(b)

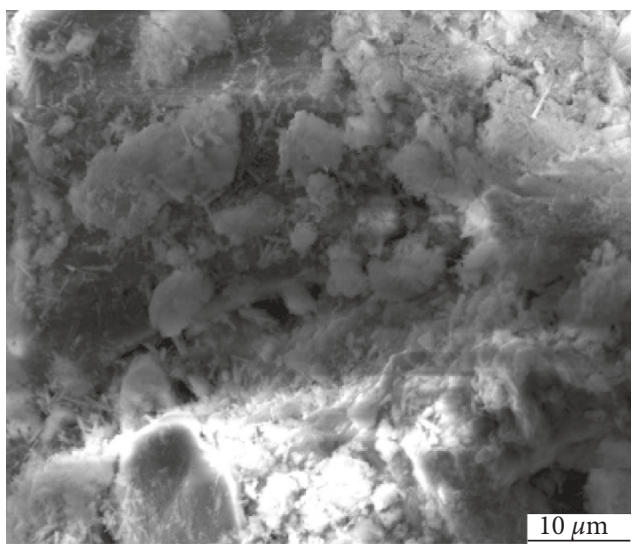

(d)

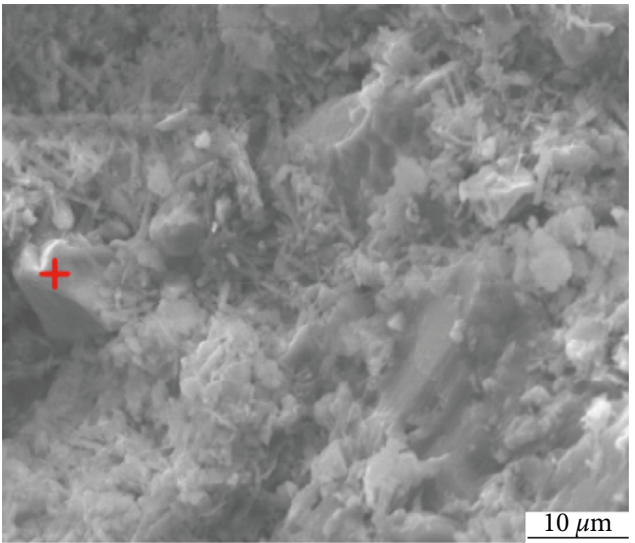

(f)

Figure 2: SEM images of CPB at different curing times. (a) $3 \mathrm{~d}$. (b) $7 \mathrm{~d}$. (c) $14 \mathrm{~d}$. (d) $28 \mathrm{~d}$. (e) $56 \mathrm{~d}$. (f) $90 \mathrm{~d}$.

development. Later the UCS increases slightly due to a small decrease in porosity.

The change of the number of pores in the development process is shown in Figure 5(b). During the development process, the number of pores decreases fast first and then the decreasing trend becomes slower. The particles tend to attach to each other and become staggered, resulting in the decrease in the gap between particles. Some gaps are filled 


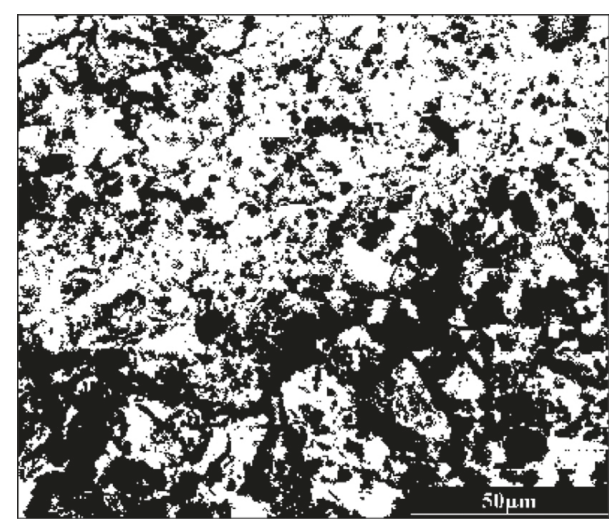

Figure 3: Binary image.

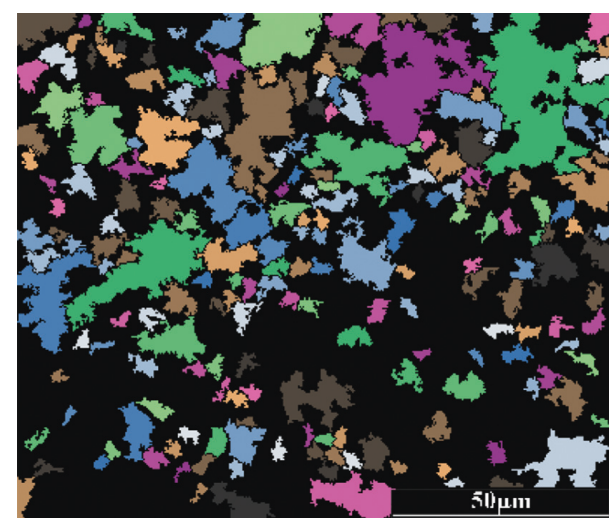

Figure 4: Vector image.

and disappeared, thus reducing the number of pores. As shown in Figure 5(b), the sensitivity of UCS to the pore number is significantly greater at the late age of $\mathrm{CPB}$ development than that at the early stage.

The variation of the UCS with the change in average pore area is shown in Figure 5(c). In the microscopic point of view, the pores are gradually filled out by the hydration products when the pore size is in a certain range. It can be seen from Figure 5(c) that the average pore area decreases significantly with the curing time at the early age of $\mathrm{CPB}$ development but keeps almost unchanged at the late age. As shown in Figure 5(c), the UCS increases with a decrease in average pore area in the whole curing period of 90 days. And yet the UCS enhances faster at the early stage of CPB development than at the late age as the average pore area reduces.

3.1.2. Characteristics of Pore Size Distribution. Figure 6 shows the proportion of the pore number versus pore area in different curing ages of CPB. It can be seen that the pores in CPB whose areas are less than 500 pixels occupy the highest proportion, from $67 \%$ to $93 \%$ in different curing stages. Furthermore, their percentages before 14 days of curing time are obviously higher than those in the subsequent curing age. When the curing time is 28 days, the proportion of pores larger than 3000 pixels increases significantly and then reduces gradually with the longer curing period. The formation of the larger pores may be attributable to the depletion of water in the $\mathrm{CPB}$ (i.e., hydration and evaporation) or the swelling of $\mathrm{CPB}$ during the hydration process. With the development of $\mathrm{CPB}$, these larger pores are filled or split into smaller pores by hydration products. Accordingly, proportions of smaller pores increase. As an example, the percentage of pores with areas between 500 pixels and 1000 pixels increases from $9.3 \%$ after 28 days of curing to $16 \%$ after 90 days of curing. Although the proportion of fine pores (less than 500 pixels) drops at the late age, shown in Figure 6, the UCS of CPB still increases due to the decrease in porosity and pore number as given in Figure 5.

Fractal theory has been applied to study various phenomena in nature for decades. In geotechnical engineering, fractal theory is often used in the study of rock fracture characteristics, pore distribution, and seepage characteristics [22-24]. Although the pore network of CPB does not strictly follow the self-similar principle, it has a statistically selfsimilar fractal structure.

The porosity fractal dimension [25] is a quantitative indicator used to describe the pore scale distribution of $\mathrm{CPB}$, which can directly reflect the changes in the pore scale which is usually described as a distribution feature of the number of voids $N(\leq r)$ less than a certain pore size $(r)$. It can be seen from the mass distribution characteristics that these two parameters have good power function correspondence, that is,

$$
\begin{gathered}
N(\leq r) \propto r^{-\mathrm{Dc}}, \\
N(\geq r)=M-N(\leq r),
\end{gathered}
$$

where $M$ is the number of total pores, which is a constant and $N(\geq r)$ is the number of pores that are larger than a certain pore size.

As $M$ is constant, and $N(\leq r)$ and $N(\geq r)$ have a constant corresponding relationship, so the established relationship $N(r) \propto r^{-D c}$ is also true. Dc was defined as the porosity fractal dimension. At different $r$, there is a corresponding $N(r)$. Dc was calculated as

$$
\mathrm{Dc}=-\lim \frac{\ln N(r)}{\ln r} \text {. }
$$

A larger Dc indicates a lower degree of uniformity and a larger difference in pore size. Figure 7 shows the relationship of porosity fractal dimension and UCS. Dc decreases quickly at the early age of $\mathrm{CPB}$ development but drops more and more slowly with longer curing age and even almost remains unchanged in the late age, suggesting the pores become more homogeneous, which is consistent with the changes in characteristics of pore size discussed in Section 3.1.1. With a decrease in Dc, the UCS increases monotonically and is more sensitive to Dc at the late age.

3.2. Characteristics of Pore Orientation. Probability entropy [26] is a quantitative parameter that reflects the order of the structural elements, which can be used to describe the overall 

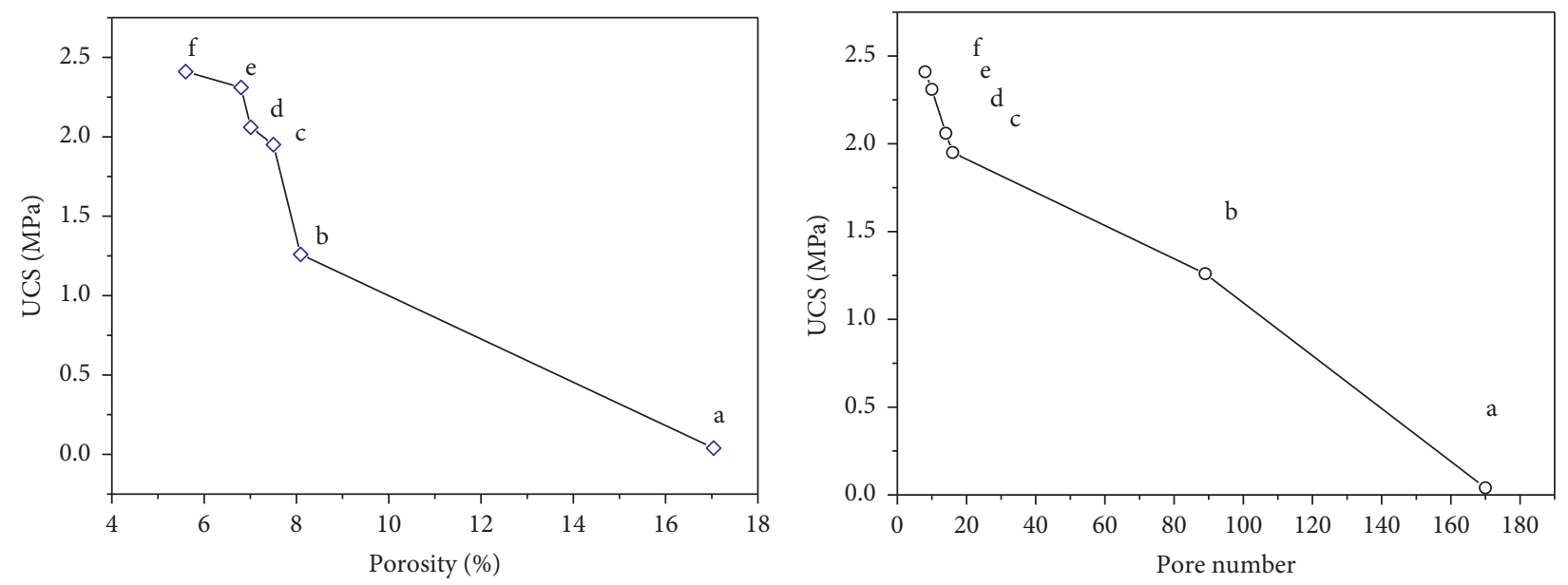

$\begin{array}{ll}\text { Curing time } & \\ \text { a: } 3 d & \text { d: } 28 d \\ \text { b: } 7 d & \text { e: } 56 d \\ \text { c: } 14 d & \text { f: } 90 d\end{array}$

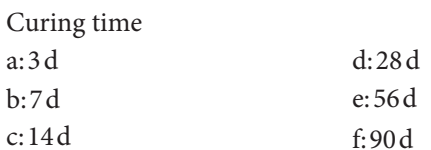

(a)

(b)

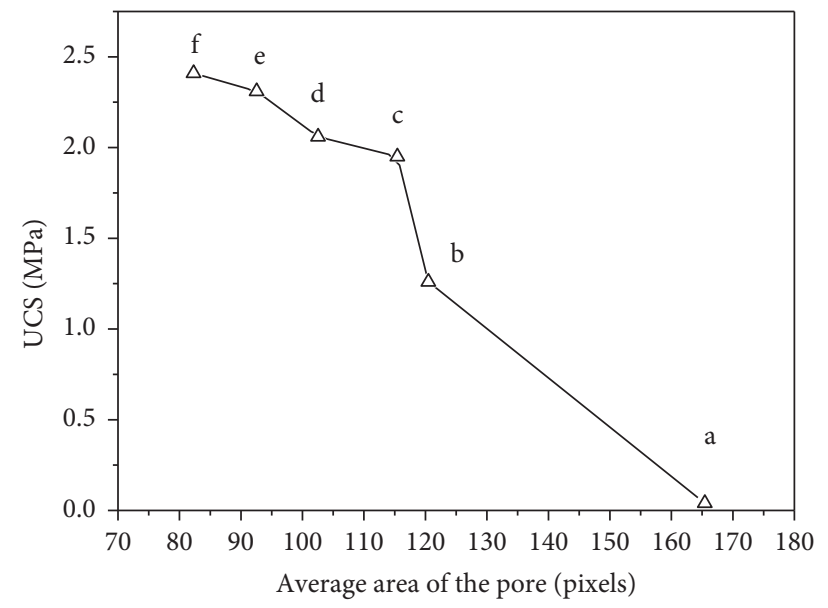

$\begin{array}{ll}\text { Curing time } & \\ \text { a: } 3 \mathrm{~d} & \mathrm{~d}: 28 \mathrm{~d} \\ \mathrm{~b}: 7 \mathrm{~d} & \mathrm{e}: 56 \mathrm{~d} \\ \text { c: } 14 \mathrm{~d} & \mathrm{f}: 90 \mathrm{~d}\end{array}$

(c)

Figure 5: Variation of UCS with characteristics of pore size. (a) Porosity. (b) Pore numbers. (c) Average area of the pore.

arrangement of porosity in the aging period. The probability entropy $\left(H_{\mathrm{m}}\right)$ is calculated as

$$
H_{\mathrm{m}}=\sum_{i=1}^{n} p_{i}(\alpha) \log _{n} p_{i}(\alpha),
$$

where $\alpha$ is the direction angle corresponding to the longest chord of cemented particles, $p_{i}$ is the frequency at which the structure appears in a certain orientation zone, and $n$ is the number of directional angle intervals in the direction of arrangement of structural elements. $H_{\mathrm{m}}$ is between 0 and 1 . The larger the $H_{\mathrm{m}}$, the more chaotic the arrangement of the pores, while the lower the better orderliness.
The relationship between UCS and pore probability entropy is shown in Figure 8. At the early age of CPB development, the probability entropy is larger than 0.96 , meaning that the distribution of the pores is chaotic and showing no obvious orientation. As the curing time increases, the probability entropy decreases rapidly, indicating that the order and orientation of pore arrangement are enhanced, which results in the increase of the UCS. The increasing rate of the UCS with the decrease of probability entropy reduces as the decrease of probability entropy. This is because the particles are constantly translational and twisted during the development of CPB and gradually change to stabilized distribution. At the 

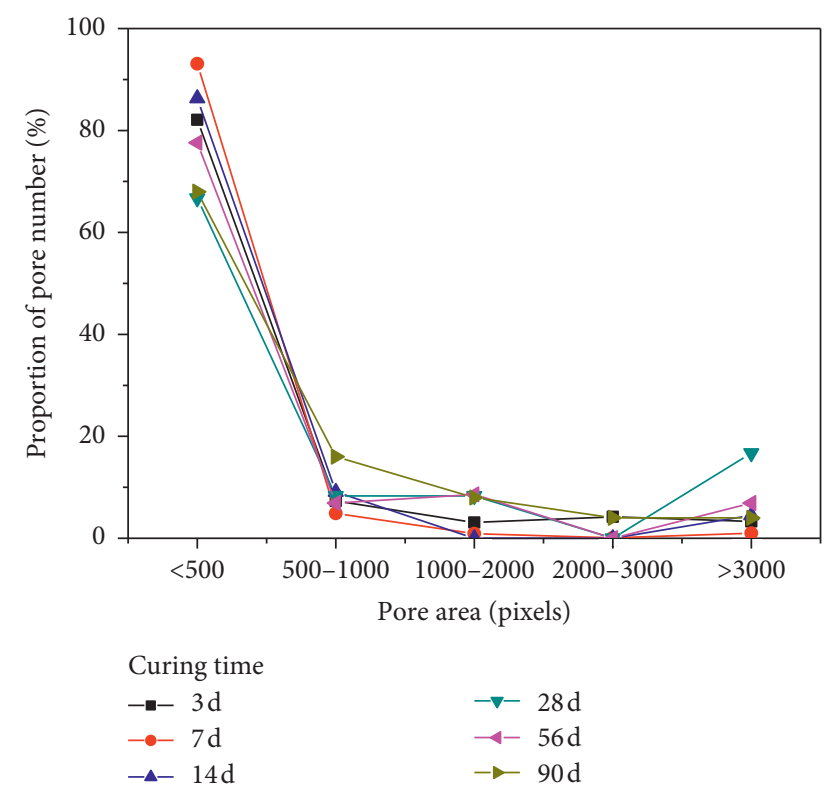

FIGURE 6: Number distribution of pore with different areas in different curing ages.

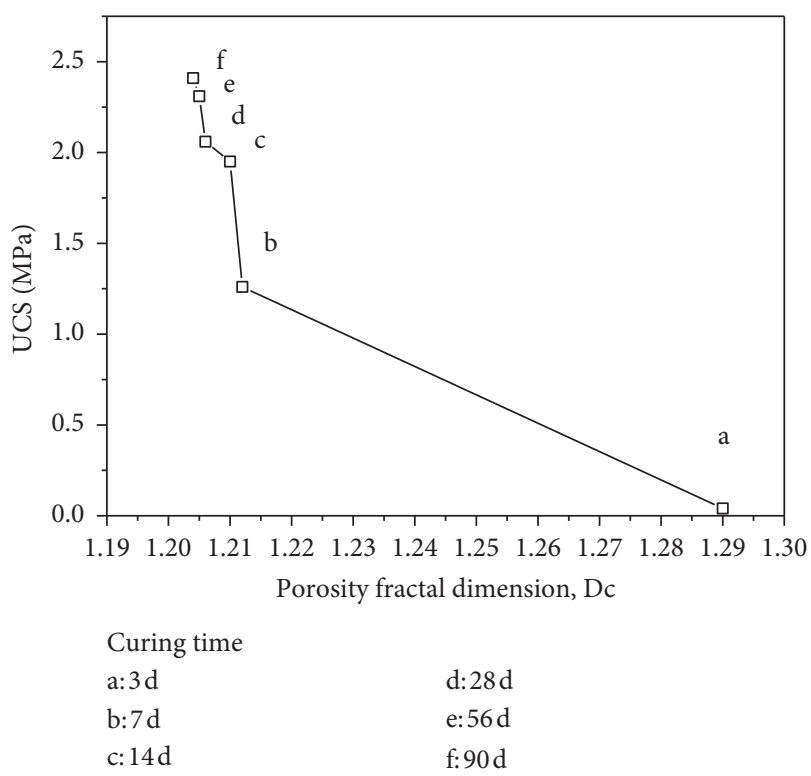

FIGURE 7: Variation in UCS with the porosity fractal dimension and the curing time.

beginning of development, most of the particles rotate. As the curing time increases, the number of rotating particles decreases, resulting in a slower change of particle and pore distribution.

The rose diagram shows the pore distribution in all directions. Figure 9 shows the pore rose diagram at different curing times. It can be seen that the distribution of pores in each direction is relatively uniform at the early age of $\mathrm{CPB}$ development. As the curing time increases, the arrangement of pores slowly gathers in one direction and becomes more ordered. This is consistent with the

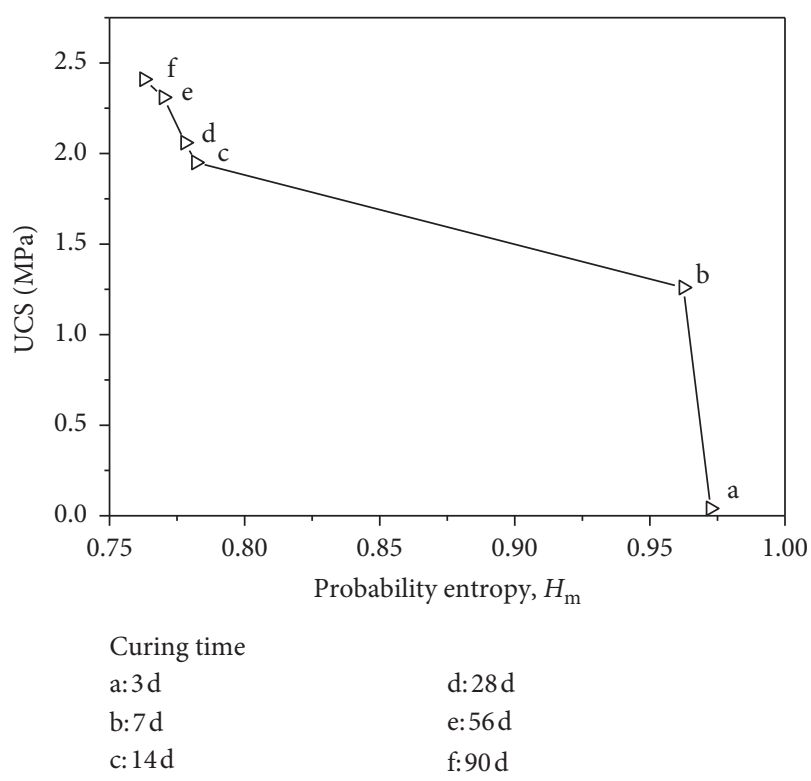

FIgURE 8: Variation in UCS with the pore probability entropy and the curing time.

abovementioned change of the probability entropy, which shows the trend of developing in a certain direction in the development of CPB.

3.3. Characteristics of Pore Morphology. The roundness of pore $i\left(R_{i}\right)$ is defined as [27]

$$
R_{i}=\frac{4 \pi S}{L^{2}}
$$

where $S$ is the area of the characterized area and $L$ is the circumference of the area. As the circularity error of a single pore was too large, the pore shape is always measured by the average circularity. The average roundness is defined as

$$
R=\sum_{i=1}^{n} \frac{R_{i}}{n}
$$

where $n$ is the number of pores. The value of $R$ is between 0 and 1 , and the larger value of $R$ means that the shape of pores is rounder overall, whereas the smaller $R$ implies that the narrower and longer pores on the whole.

The UCS as a function of the average roundness of pores and the curing time is shown in Figure 10. It can be seen from Figure 10 that the UCS approximately linearly improves with an increase in the average roundness of pores. The growth rate of average roundness is high at the early age of CPB development, then falls down gradually as the curing time increases, and finally tends to be zero at the late age. This suggests that the shape of pores gradually becomes round in the development of $\mathrm{CPB}$ and stabilizes after 90 days of curing time.

\section{Conclusions}

(a) The characteristics of pore size have a great influence on the UCS of CPB. During the development of CPB, 


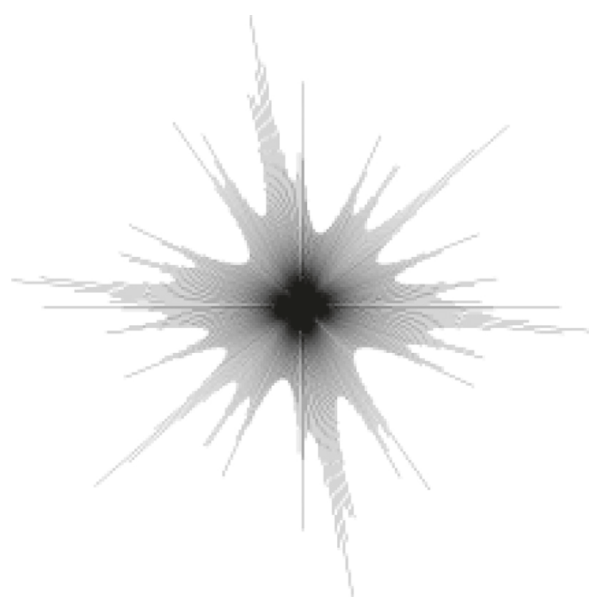

(a)

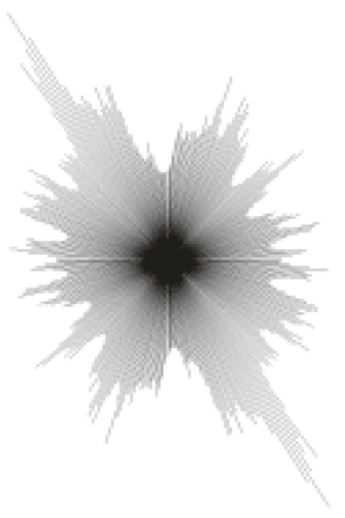

(d)

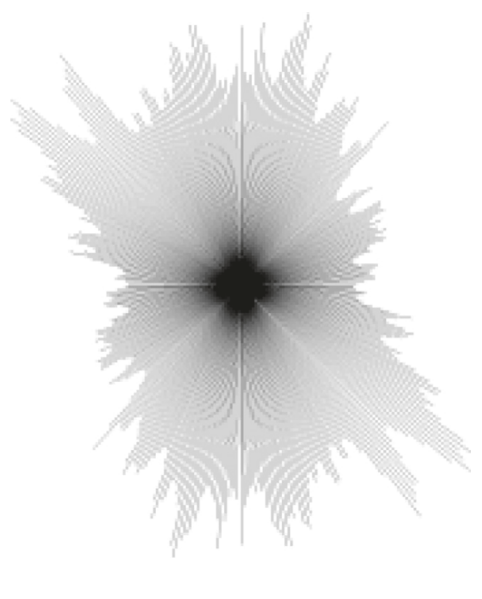

(b)

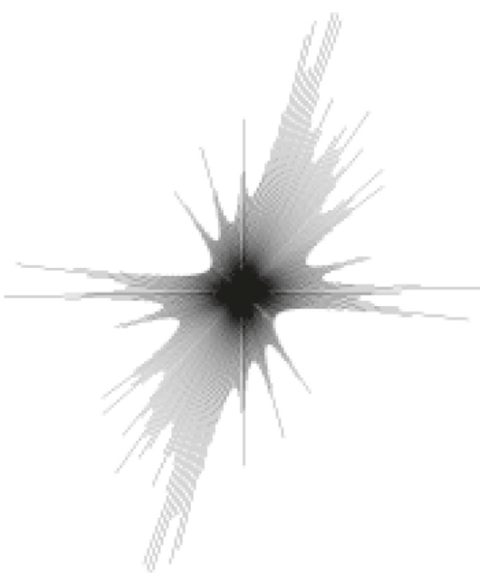

(e)

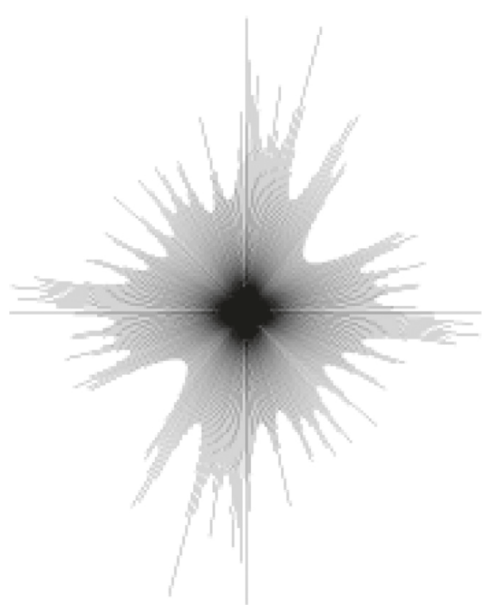

(c)

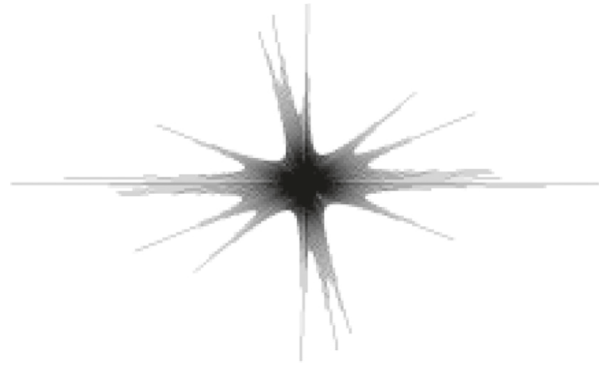

(f)

Figure 9: The rose diagrams of pores at different curing times. (a) 3 d. (b) 7 d. (c) 14 d. (d) 28 d. (e) 56 d. (f) 90 d.

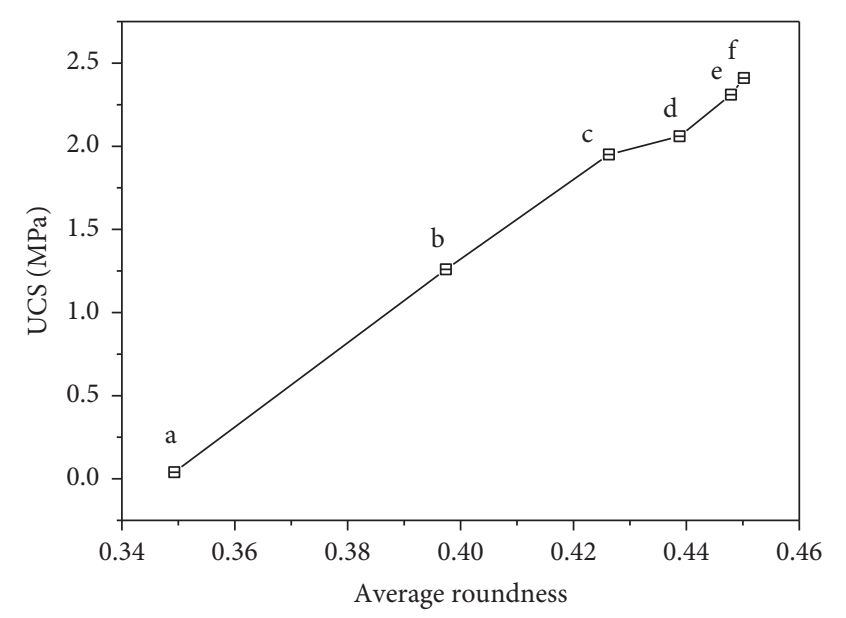

$\begin{array}{ll}\text { Curing time } & \\ \text { a: } 3 d & \text { d: } 28 d \\ \text { b: } 7 d & \text { e: } 56 d \\ \text { c: } 14 d & \text { f: } 90 d\end{array}$

FIGURE 10: Variation in UCS with the average roundness of pores and the curing time. the porosity, pore number, and average pore area decrease monotonically, dropping sharply first and then slowing down and stabilizing. The UCS of CPB varies similarly as a function of these feature parameters in regard to the pore size.

(b) The characteristics of arrangement of the pores have an obvious effect on the USC of CPB. At the early age of $\mathrm{CPB}$ development, the probability entropy is greater than 0.96 , indicating a chaotic pore distribution and no obvious orientation. At the late age of $\mathrm{CPB}$ development, the probability entropy becomes smaller and the order and orientation of the pore distribution are enhanced, resulting in an increase in USC.

(c) The characteristics of pore morphology also greatly affect the UCS of CPB. The relationship between the UCS and the average roundness of pores is approximately positive linear. The growth rate of pore average roundness decreases with the development of $\mathrm{CPB}$, approaching zero after 90 days of curing time. 


\section{Data Availability}

The data used to support the findings of this study are included within the article.

\section{Conflicts of Interest}

The authors declare that there are no conflicts of interest regarding the publication of this paper.

\section{Acknowledgments}

This research was supported by the National Natural Science Foundation of China (no. 51504182, 51674188, 51404191, and 51405381), the Natural Science Basic Research Plan of Shaanxi Province of China (no. 2015JQ5187, 2018JQ5183, 2018JM5161), the Scientific Research Program funded by the Shaanxi Provincial Education Department (no. 15JK1466), the Project funded by China Postdoctoral Science Foundation (no. 2015M582685), and Outstanding Youth Science Fund of Xi'an University of Science and Technology (no. 2018YQ2-01). This research was also supported by the National Research Council of Science \& Technology (NST) grant by the Korea government (MSIP) (no. CRC-16- 38502KICT).

\section{References}

[1] J. Chen, J. P. Du, W. S. Zhang, and J. X. Zhang, "An elastic base beam model of overlying strata movement during coal mining with gangue back-filling," Journal of China University of Mining \& Technology, vol. 41, no. 1, pp. 14-19, 2012.

[2] S. J. Cai, Mine Filling Mechanics Foundation, Metallurgical Industry Press, Beijing, China, 2009.

[3] T. Belem and M. Benzaazoua, "Design and application of underground mine paste backfill technology," Geotechnical and Geological Engineering, vol. 26, no. 2, pp. 147-174, 2008.

[4] R. L. Hu, Z. Q. Yue, L. C. Wang, and S. J. Wang, "Review on current status and challenging issues of land subsidence in China," Engineering Geology, vol. 76, no. 1-2, pp. 65-77, 2004.

[5] R. Rankine, M. Pacheco, and N. Sivakugan, "Underground mining with backfills," Soils \& Rocks, vol. 30, no. 2, pp. 93-101, 2007.

[6] Y. L. Huang, J. X. Zhang, Q. Zhang, S. J. Nie, and B. F. An, "Strata movement control due to bulk factor of backfilling body in fully mechanized backfilling mining face," Journal of Mining and Safety Engineering, vol. 29, no. 2, pp. 162-167, 2012.

[7] A. Kesimal, B. Ercikdi, and E. Yilmaz, "The effect of desliming by sedimentation on paste backfill performance," Minerals Engineering, vol. 16, no. 10, pp. 1009-1011, 2003.

[8] M. Fall, J. C. Célestin, M. Pokharel, and M. Touré, "A contribution to understanding the effects of curing temperature on the mechanical properties of mine cemented tailings backfill," Engineering Geology, vol. 114, no. 3-4, pp. 397-413, 2010.

[9] D. Q. Deng, L. Liu, Z. L. Yao, K. I. Song, and D. Z. Lao, “A practice of ultra-fine tailings disposal as filling material in a gold mine," Journal of Environmental Management, vol. 196, pp. 100-109, 2017.

[10] C. You, J. Qian, J. Qin, H. T. Wang, Q. Z. Wang, and Z. Q. Ye, "Effect of early hydration temperature on hydration product and strength development of magnesium phosphate cement (MPC)," Cement and Concrete Research, vol. 78, pp. 179-189, 2015.

[11] B. Gaël, T. Christelle, E. Gilles, G. Sandrine, and S. F. Tristan, "Determination of the proportion of anhydrous cement using SEM image analysis," Construction and Building Materials, vol. 126, pp. 157-164, 2016.

[12] X. J. Deng, J. X. Zhang, B. Klein, N. Zhou, and B. deWit, "Experimental characterization of the influence of solid components on the rheological and mechanical properties of cemented paste backfill," International Journal of Mineral Processing, vol. 168, pp. 116-125, 2017.

[13] H. Zhou, Y. G. Fang, and C. J. Yu, "Micro-structure observation and analysis of Guangzhou soft soil during consolidation process," Chinese Journal of Rock Mechanics and Engineering, vol. 28, pp. 3830-3837, 2009.

[14] Y. Cao, J. Zhou, and J. J. Yan, "Study of microstructures of soft clay under dynamic loading considering effect of cyclic stress ratio and frequency," Rock and Soil Mechanics, vol. 35, no. 3, pp. 735-743, 2014.

[15] J. Zhou, Y. L. Deng, Y. Cao, and J. Yan, "Experimental study of microstructure of Hangzhou saturated soft soil during consolidation process," Journal of Central South University, vol. 45, no. 6, pp. 1998-2005, 2014.

[16] W. B. Xu, W. D. Pan, and M. L. Ding, "Experiment on evolution of microstructures and long-term strength model of cemented backfill mass," Journal of Central South University (Science and Technology), vol. 46, no. 6, pp. 2333-2341, 2015.

[17] L. Liu, K. I. Song, D. Z. Lao, and T. H. Kwon, "Rheological properties of cemented tailing backfill and the construction of a prediction model," Materials, vol. 8, no. 5, pp. 2076-2092, 2015.

[18] M. Fall and M. Benzaazoua, "Modeling the effect of sulphate on strength development of paste backfill and binder mixture optimization," Cement and Concrete Research, vol. 35, no. 2, pp. 301-314, 2005.

[19] C. Liu, B. Shi, J. Zhou, and C. Tang, "Quantification and characterization of microporosity by image processing, geometric measurement and statistical methods: application on SEM images of clay materials," Applied Clay Science, vol. 54, no. 1, pp. 97-106, 2011.

[20] A. Khaldoun, L. Ouadif, K. Baba, and L. Bahi, "Valorization of mining waste and tailings through paste backfilling solution, Imiter operation, Morocco," International Journal of Mining Science and Technology, vol. 26, no. 3, pp. 511-516, 2016.

[21] X. M. Wang, B. Zhao, and Q. L. Zhang, "Cemented backfill technology based on phosphorous gypsum," Journal of Central South University of Technology, vol. 16, no. 2, pp. 285-291, 2009.

[22] S. M. Yi, Z. H. Li, and Y. Z. Zhang, "The fractal characteristics of fractures in expansion soil and its significance," Chinese Journal of Geotechnical Engineering, vol. 21, no. 3, pp. 294298, 1999.

[23] J. Shen, W. S. Zhu, and Y. S. Zhao, "Fractal distribution for rock mass in fractures for rock mass in high slopes and its application to the lock of three gorges," Chinese Journal of Geotechnical Engineering, vol. 20, no. 5, pp. 97-100, 1998.

[24] Y. Zhao, X. H. Li, Y. Y. Lu, and X. G. Jin, "Hydraulic model of rock mass with block fracture slope and its numerical simulation," Rock and Soil Mechanics, vol. 26, no. 6, pp. 995-999, 2005.

[25] L. T. Mao, R. Xue, L. Q. An, and H. Q. Li, "Fractal approach on soft soil porosity microstructure," Journal of China University of Mining and Technology, vol. 34, no. 5, pp. 600-604, 2005. 
[26] B. Shi, "Quantitative research on the orientation of microstructures of clayey soil," Acta Geologica Sinica, vol. 52, no. 2, pp. 36-44, 1997.

[27] S. W. Wu, C. H. Yang, C. Zhang, H. J. Mao, and H. R. Li, "Microscopic geometric characteristics of surface sedimentary tailings," Chinese Journal of Rock Mechanics and Engineering, vol. 35, no. 4, pp. 768-777, 2016. 


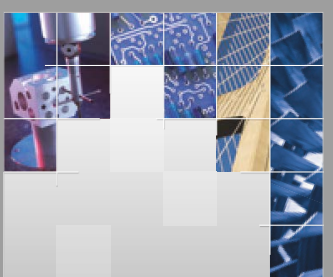

\section{Enfincering}
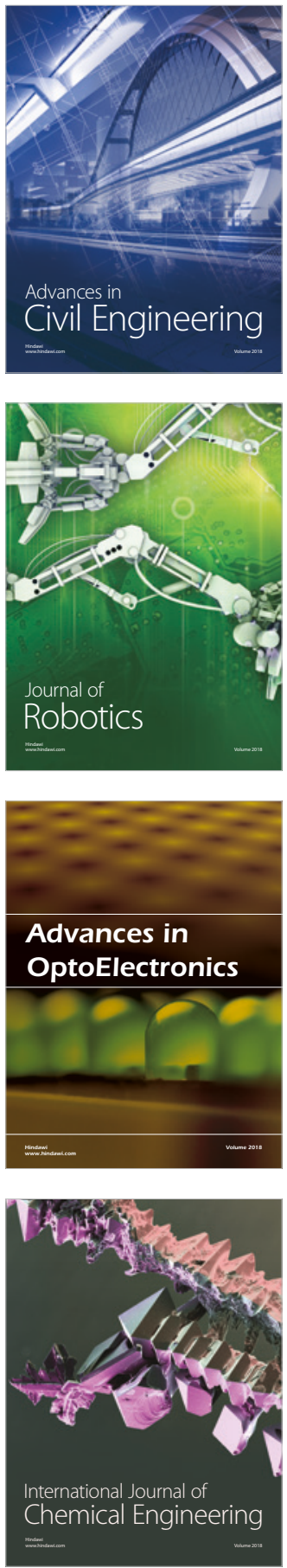

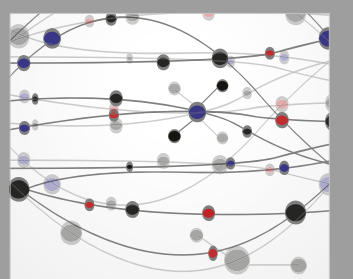

\section{Rotating \\ Machinery}

The Scientific World Journal

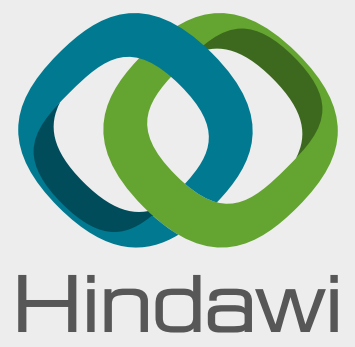

Submit your manuscripts at

www.hindawi.com
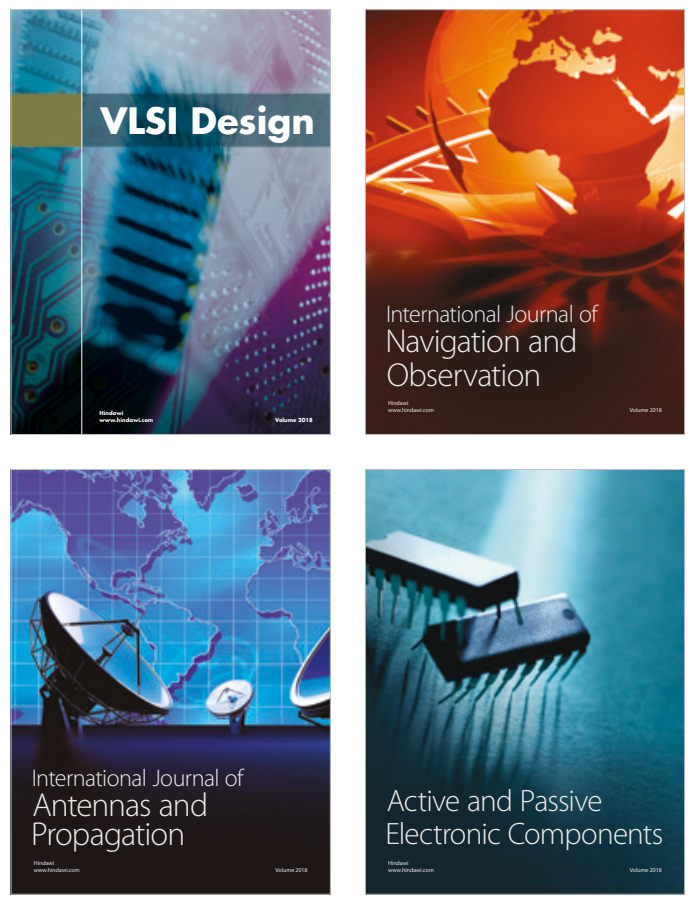
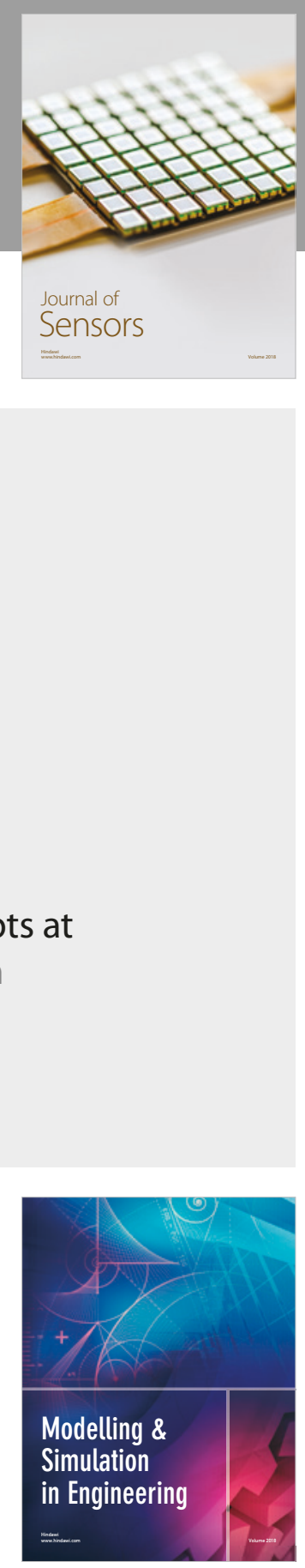

\section{Advances \\ Multimedia}
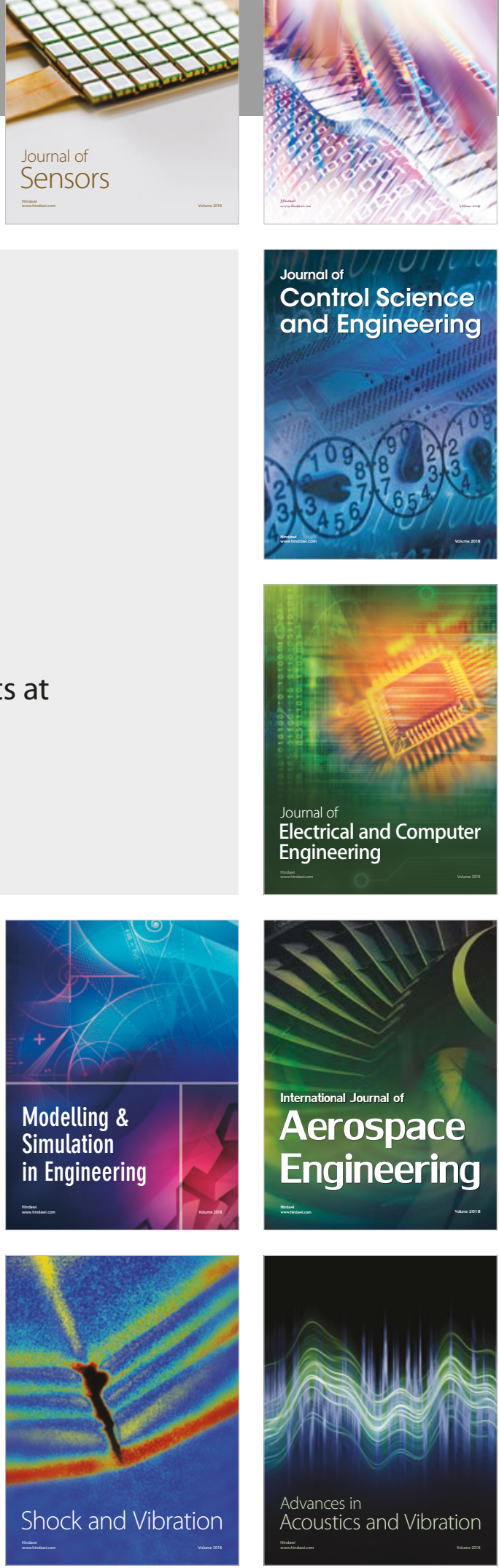